\title{
O desenvolvimento humano sob a perspectiva do viver mais e melhor: análise do acesso e das condições de saúde da população idosa de Santa Maria (RS)
}

\author{
Cristiéle de Almeida Vieira* \\ Caroline Lucion Puchale** \\ Diogo Alberto de Moraes**** \\ Sibele Vasconcelos de Oliveira ${ }^{* * * * *}$
}

\begin{abstract}
Resumo
O processo de envelhecimento da população brasileira tem desafiado o Estado brasileiro quanto à sua capacidade de atender às demandas do estrato social composto pelos idosos. De fato, a expansão da população idosa no país motiva reflexões acerca dos instrumentos desenvolvidos em prol da seguridade social. Diante desse contexto, o presente estudo tem por objetivo analisar o acesso e as condições de saúde dos idosos residentes na região nordeste de Santa Maria, RS. Para tanto, realizaram-se pesquisas bibliográficas e documentais, bem como pesquisa de campo. Os dados primários coletados durante o interstício de 2015 e 2016 foram manipulados por meio do método fuzzy, que permitiu analisar a existência de privações em saúde, os indicadores em que estão focalizadas e o grau de recorrência que são percebidas pela população idosa do referido município. Os resultados apontam alta privação no acesso a serviços de saúde e alimentação, especificamente nas consultas odontológicas e refeições diárias.
\end{abstract}

Palavras-chaves: Economia da saúde. Teoria dos conjuntos fuzzy. Desenvolvimento humano.

* Doutoranda em Economia Aplicada na Universidade Federal do Rio Grande do Sul. Mestra em Teoria Econômica pela Universidade Estadual de Maringá. Bacharela em Ciências Econômicas pela Universidade Federal de Santa Maria. Bolsista CNPq. E-mail: crissavieira@gmail.com

** Doutoranda em Economia Aplicada na Universidade Federal do Rio Grande do Sul. Mestra em Economia e Desenvolvimento pela Universidade Federal de Santa Maria. Bacharela em Ciências Econômicas pela Universidade Federal de Santa Maria. Bolsista Capes. E-mail: carolpuchale@gmail.com

*** Mestre em Desenvolvimento Econômico na Universidade Federal do Paraná. Bacharel em Ciências Econômicas pela Universidade Federal de Santa Maria. E-mail: diogomoraes_idp@yahoo.com.br

${ }^{* * * *}$ Professora do Departamento de Economia e Relações Internacionais e do Programa de Pós-graduação em Economia e Desenvolvimento da Universidade Federal de Santa Maria. Doutora em Agronegócios pela Universidade Federal do Rio Grande do Sul. Mestra em Extensão Rural pela Universidade Federal do Rio Grande do Sul. Bacharela em Ciências Econômicas pela Universidade Federal de Santa Maria. E-mail: sibele.oliveira@ufsm.br

http://doi.org/10.5335/rtee.v25i53.8536

Submissão: 19/08/2018. Aceite: 18/09/2020.

Teoria e Evidência Econômica - a. 25, n. 53, p. 224-242, jul./dez. 2019 


\section{Introdução}

Pelas contribuições que realizou ao tema do bem-estar social, Amartya Sen foi agraciado com o Prêmio Nobel em Economia (1998). Na oportunidade, o professor de Economia e Filosofia nas Universidades de Harvard e Thomas Lamont defendeu a tese de que a qualidade de vida das populações é influenciada, dentre outras razões, por oportunidades econômicas, liberdades políticas, poderes sociais e por condições habilitadoras. Dentre outros influentes, são determinantes para a promoção do bem-estar social as liberdades substantivas, como os incentivos sociais que os indivíduos recebem, o acesso à educação básica e ao gozo de plena saúde (SEN, 2010).

Nesse sentido, as reflexões sobre condições de vida da população permitem às sociedades repensar estratégias para o desenvolvimento de instrumentos de reprodução social. Em especial, permite-nos repensar sobre as transformações sociais observadas na sociedade brasileira nas últimas décadas e sobre sua capacidade de superar realidades imersas em vulnerabilidades socioeconômicas.

Destarte, o processo de envelhecimento da população brasileira tem suscitado a discussão acerca das condições de vida e privações vivenciadas pelo estrato social dos idosos. Conforme informações disponibilizadas pelo Instituto Brasileiro de Geografia e Estatística (IBGE) (2018), os idosos já representam 14,4\% dos brasileiros e, em 2060, representarão $25 \%$ da população total. Sobretudo, as estatísticas apresentadas fomentam o debate sobre os desafios do Estado brasileiro no tocante à oferta de previdência privada e à assistência à saúde ao público idoso.

Assim sendo, por meio de um estudo de caso, a presente pesquisa tem por objetivo analisar o acesso e as condições de saúde dos idosos na contemporaneidade. A partir da análise de dados primários, coletados por meio de entrevistas realizadas nos anos de 2015 e 2016 entre idosos residentes na região nordeste de Santa Maria, RS, institui-se a avaliação das múltiplas dimensões associadas ao desenvolvimento de liberdades substantivas e individuais. Especificamente, emprega-se ferramentais analíticos fuzzy para estimar as fontes e os graus de recorrência de privações no que concerne às condições de saúde dos idosos santamarienses.

Embasados em pesquisa bibliográfica e documental, foram desenvolvidos sistemas de inferência fuzzy para representar as condições de acesso à saúde e as privações em vida desta que é uma das populações com expressiva propensão ao desenvolvimento de vulnerabilidades socioeconômicas. Para tanto, duas dimensões de análise e sete indicadores foram avaliados, de forma a representar a multidimensionalidade do fenômeno vinculado às privações. 
A redação está organizada em cinco seções, incluindo esta introdução. A seguir, discorre-se sobre as relações entre a temática da saúde e do desenvolvimento humano. Os procedimentos metodológicos são apresentados na seção 3. A seção 4 dedica-se à apresentação e à discussão dos principais resultados da pesquisa. Por fim, são demonstradas as considerações finais e as referências consultadas durante a realização das pesquisas bibliográficas e documentais.

\section{A relação entre saúde e desenvolvimento humano}

Há na literatura recente intenso debate acerca do tema desenvolvimento: de um lado, os defensores do crescimento econômico como único e suficiente agente de bem-estar social; de outro, encontram-se aqueles favoráveis ao conceito multidimensional do desenvolvimento humano. Nesse contexto, Sen (2010) afirma que o crescimento econômico é importante meio para o desenvolvimento de melhores condições de vida para a população, mas também são pertinentes as avaliações acerca das múltiplas privações que acometem os excluídos dos benefícios orientados pelo mercado.

O desenvolvimento como liberdade defendido por Sen (2010) refere-se à expansão além das liberdades econômicas, incluindo também liberdades sociais e políticas. Assim sendo, envolve o processo de remoção das principais fontes de privação à população, tais como pobreza e tirania, negligência dos serviços públicos em saúde, educação, entre outros fatores que interferem diretamente no bem-estar da sociedade. Em síntese, argumenta-se que, para gerar desenvolvimento, são necessárias a promoção de mudanças no âmbito social e o crescimento administrado que leve ao aumento da qualidade de vida da população (CASSOL; NIEDERLE, 2016).

Tanto Sen (1999) quanto Deaton (2003) afirmam que saúde é um componente básico e importante para o desenvolvimento humano. Segundo Sen (1999), a saúde por si só é uma parte constitutiva do bom desenvolvimento: i) pelo lado econômico, a boa saúde e a prosperidade econômica apoiam-se mutuamente, sendo que indivíduos saudáveis estão mais propensos a auferir maior renda; ii) pelo lado social, discute-se sobre as condições de reprodução de maiores expectativas de vida, que só são concretizadas com boa saúde e que estão relacionadas com as oportunidades sociais ofertadas aos indivíduos (políticas epidemiológicas, assistência médica, instalações educacionais).

De acordo com Giacomelli, Marin e Feistel (2017), entre os fatores que justificam a realização de estudos em saúde populacional, está o entendimento de que os problemas de saúde podem proporcionar o agravamento e a perpetuação da 
pobreza. De fato, os estratos sociais mais vulneráveis a doenças e privações no que concerne ao acesso a serviços básicos e cuidados com a saúde são os pobres. Wagstaff et al. (2004) afirmam que existe uma relação bidirecional entre o fenômeno da pobreza e o surgimento de possíveis doenças, pois as enfermidades podem afetar diretamente o rendimento familiar. Indaga-se também que, em países com maior nível de pobreza, há maior ocorrência de diversas doenças. Os indivíduos considerados pobres veem-se encurralados em um ciclo vicioso: a pobreza é condicionada pelo estado de doença, e esta última condiciona a pobreza.

Em opinião correlata, o estudo de Novignon et al. (2012) mostrou que o estado de saúde de um agregado familiar desempenha papel crucial na determinação da vulnerabilidade à pobreza. Segundo os autores, à medida que a saúde geral do agregado familiar diminui, espera-se que no futuro o agregado familiar torne-se mais vulnerável à pobreza. Novignon et al. (2012) ainda destacam que, além dos fatores de saúde individuais, o acesso a serviços básicos é crucial na análise. Da mesma forma, segundo Heller (1998), os riscos de saneamento afetam com maior intensidade as populações de status socioeconômico menor. Isto é, a saúde do indivíduo está ligada a dois fatores principais: ao estado de saúde, além do acesso e ao uso de serviços de saúde pública para ações preventivas ou assistenciais (BARATA, 2009).

Para Sen (2010), o indivíduo que não tem acesso a bens essenciais, possivelmente, não conseguirá levar a vida que gostaria, pois a possibilidade de obter outros bens é limitada. Como exemplo, pode-se imaginar um indivíduo que não tem acesso a hospitais ou postos de saúde para exames de rotina. Essa restrição poderá fragilizar seu organismo e permitir o surgimento de doenças no longo prazo e, consequentemente, reduzir a capacitação de obter um emprego, afetando sua qualidade de vida e a capacidade de reprodução social. Nesta mesma linha de análise, Barata (2009) evidencia que a relação entre saúde e renda não é linear, mas uma parábola, ou seja, a partir de um certo limiar, os aumentos de riqueza não se traduzem em mais saúde.

Com o processo de envelhecimento da população, a atenção para o bem-estar do idoso tem ganhando espaço na literatura. Segundo Camacho e Coelho (2010), quanto maior for o acesso a bens e serviços da sociedade, maior será a qualidade de vida do processo de envelhecimento. Em mesma perspectiva, Sousa, Galante e Figueiredo (2003) afirmam que desenvolver meios para atender às dificuldades do crescente grupo de idosos é importante para seu bem-estar e desenvolvimento das sociedades contemporâneas.

Pereira et al. (2011) destacam que atingir maiores níveis de longevidade é um êxito do século XX, porém esta conquista social deve ser acompanhada de 
qualidade, ou seja, proporcionar um envelhecimento da população com anos bem vividos e saudáveis. Os autores apontam que analisar as condições sociossanitárias dos idosos é uma estratégia para identificar os principais indicadores de bem-estar da velhice. Logo, os planejadores de políticas públicas devem dar atenção especial às características sanitárias, que tradicionalmente são configuradas como fatores de risco à população e que têm levado a uma baixa qualidade de vida.

Além disso, Costa et al. (2012) recordam que o envelhecimento produzirá um aumento da demanda por serviços de saúde e, como efeito, haverá elevação progressiva do custo da saúde pública. Os autores também atentam que é necessário que se comece desde já uma reforma na seguridade social para atender às demandas sociais de uma nova realidade demográfica. Assim, vê-se que o desenvolvimento econômico sustentado está diretamente relacionado ao desenvolvimento humano saudável, pois, para que os idosos do presente e do futuro colaborem ativamente na economia, é preciso iniciar um processo de melhoramento da qualidade de vida desta população.

Em síntese, pode-se dizer que o mapeamento das maiores necessidades da saúde do idoso torna-se importante por vários motivos, a saber: i) uma maior qualidade de vida desta população idosa interfere diretamente na capacidade de desenvolvimento econômico do país; ii) um aumento no desenvolvimento humano dos idosos implica na ampliação do desenvolvimento humano do país, já que dentro de alguns anos será constituinte da maior parte da população brasileira; iii) pela atenção às políticas públicas, como reformas na seguridade social.

Na próxima seção será explanada a metodologia utilizada para analisar a saúde do idoso em alguns bairros do município de Santa Maria, RS, localizado na região central do estado do Rio Grande do Sul. Tendo em vista a realização de pesquisa de campo, empregou-se a análise de estudo de caso, com a finalidade de explorar dados específicos sobre a temática.

\section{Metodologia}

\section{Ferramentais analíticos empregados: o desenvolvimento de sistemas de inferência fuzzy}

A lógica fuzzy é uma forma de lógica multivalorada em que os valores respostas das variáveis podem assumir qualquer valor entre 0 (falso) e 1 (verdadeiro). Sua aplicação se dá em diversas áreas do conhecimento e permite que conceitos não 
facilmente quantificáveis sejam expressos em variáveis numéricas. Jané (2004) considera que a teoria dos conjuntos fuzzy é capaz de traduzir fenômenos de ambiguidade, imprecisão ou nebulosidade, através de regras preestabelecidas, em que o resultado final não é completamente falso ou verdadeiro, mas resultados parciais com intervalos de pertencimento. Trazendo tal diferença para o contexto das vulnerabilidades em saúde, por exemplo, a lógica difusa permite que um mesmo indivíduo esteja situado $70 \%$ na categoria privada e $30 \%$ na categoria de média privação.

De modo geral, a teoria dos conjuntos fuzzy busca sintetizar contextos de incerteza em modelos matemáticos inteligíveis. No trabalho em questão, utiliza-se variáveis linguísticas para definir o estado do indivíduo em relação à saúde. Adjetivos como "totalmente", "parcialmente", "muito alto" e "muito baixo" são utilizados para, na condição de variáveis linguísticas, descreverem as informações em valores não numéricos. Vejamos um exemplo no Quadro 1:

Quadro 1 - Representação de um termo linguístico e seus diferentes intervalos de pertinência

\begin{tabular}{|l|l|l|}
\hline Variável linguística & \multicolumn{1}{|c|}{ Termo linguístico } & \multicolumn{1}{c|}{ Intervalo de pertinência } \\
\hline \multirow{2}{*}{$\begin{array}{l}\text { Acesso a serviços } \\
\text { básicos* }\end{array}$} & Baixa privação & Acesso a 6 serviços básicos ou mais \\
\cline { 2 - 3 } & Média privação & Acesso de 3 a 5 serviços básicos \\
\cline { 2 - 3 } & Alta privação & Acesso a menos de 2 serviços básicos \\
\hline
\end{tabular}

Fonte: Organização Mundial da Saúde (2018).

*Serviços básicos considerados: energia elétrica, água encanada/tratada/poço, drenagem para o esgoto/poço negro, iluminação pública, serviço de coleta de lixo, transporte público na comunidade, e outros.

No contexto ilustrado, um indivíduo que possui acesso a 8 serviços básicos de saúde pertence maioritariamente à categoria representada pelo termo linguístico "Baixa privação". Da mesma maneira, um indivíduo que tem acesso a 6 serviços básicos também o faz. A diferença entre tais indivíduos, no entanto, é o grau de pertencimento à categoria em que se enquadram, em virtude de sua colocação no intervalo de pertinência. Enquanto o primeiro está em grande medida inserido na categoria citada, o segundo já está em fase de transição entre a primeira e a segunda categoria, representadas respectivamente pelos termos linguísticos "Baixa" e "Média". A lógica fuzzy permite que tais diferenças sejam consideradas e processadas matematicamente, casando variáveis quantitativas e qualitativas em um mesmo modelo.

O presente trabalho utiliza o processo de inferência da lógica fuzzy, que, de acordo com Marro et al. (2010), é caracterizado pela avaliação das entradas através de regras preestabelecidas para obter conclusões sobre determinada situação. 
Tal processo consiste em três etapas principais: a de fuzzificação, a de inferência fuzzy, propriamente dita, e a de defuzzificação (Figura 1).

Figura 1 - Etapas do processo de inferência fuzzy
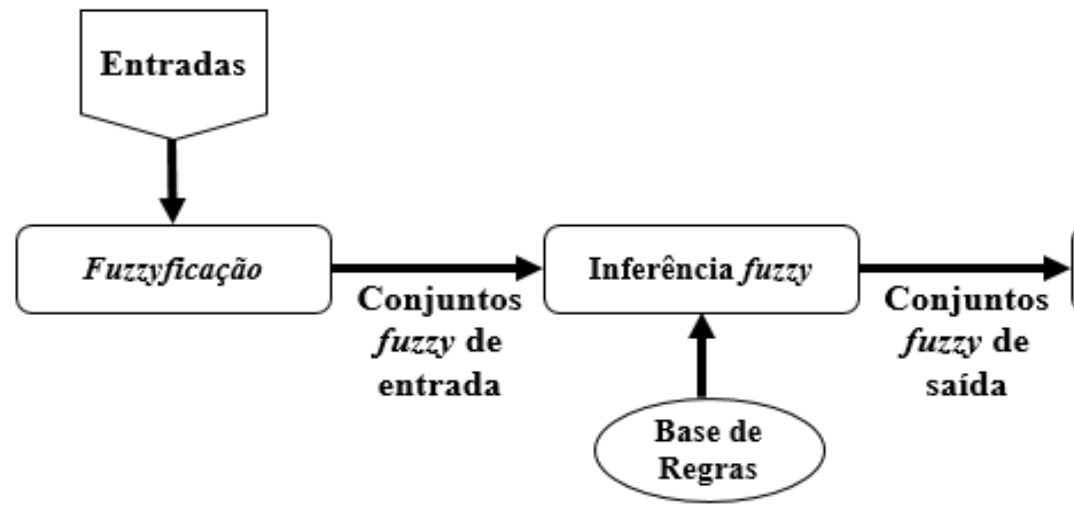

Defuzzificação

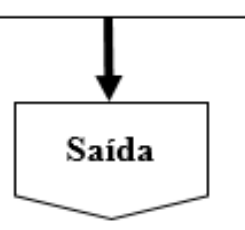

Fonte: adaptado de Antunes (2006).

A etapa de fuzzificação consiste na transformação dos dados numéricos de entrada em variáveis linguísticas fuzzy. Uma vez "fuzzificadas" as informações, tem-se a etapa de inferência, destinada a obter as variáveis de saída (ou respostas) do modelo. Na etapa de inferência, ocorre o entrelaçamento das variáveis fuzzy de entrada com as de saída, por meio da base de regras definidas pelo pesquisador.

A formação da base de regras é constituída pelos elementos de agregação e composição. O primeiro consistindo na premissa das regras, ou a parte SE; e o segundo consistindo nos resultados, ou a parte ENTÃO. Logo, temos um conjunto de regras estruturadas no formato SE-ENTÃO, que definirão os resultados da pesquisa após a realização do processo de inferência. O resultado é tal que, SE um indivíduo está enquadrado na categoria "Inadequado", ENTÃo ele é considerado privado no que diz respeito ao indicador (JANÉ, 2004; ANTUNES, 2006). Por fim, a última etapa do processo - defuzzificação - consiste na transformação das variáveis de saída linguísticas, obtidas no processo de inferência, em valores numéricos.

\section{Dados, dimensões e construção do Índice Fuzzy de Saúde}

O estudo contempla a reflexão acerca das condições de saúde da população idosa residente da região nordeste da cidade de Santa Maria, RS. Localizado no centro 
do estado do Rio Grande do Sul (Figura 2), o município ocupa 0,68\% do território estadual e possui aproximadamente 261.031 habitantes. Especificamente, habitam Santa Maria 123.634 homens (47,36\% da população total) e 137.397 mulheres (52,63\% da população total).

A região nordeste do supracitado município é composta por seis bairros - Km3, Presidente João Goulart, Itararé, Nossa Senhora das Dores, Menino Jesus e Campestre do Menino Deus, totalizando uma população de 30.463 habitantes, destes, cerca de 3.045 são pessoas com 65 anos ou mais (IBGE, 2010).

As principais vantagens dessa região para o estudo, além da facilidade de acesso, são a diversidade da área, repleta de zonas de urbanização mais intensa e outras quase rurais, e a diversidade da população, em termos de renda média e condições de moradia, composição étnica, etc. A coleta dos dados se deu ao longo dos anos de 2015 e 2016, contando com cerca de 192 respondentes idosos proporcionalmente distribuídos com base no tamanho dos bairros.

Figura 2 - Localização da cidade de Santa Maria (RS)

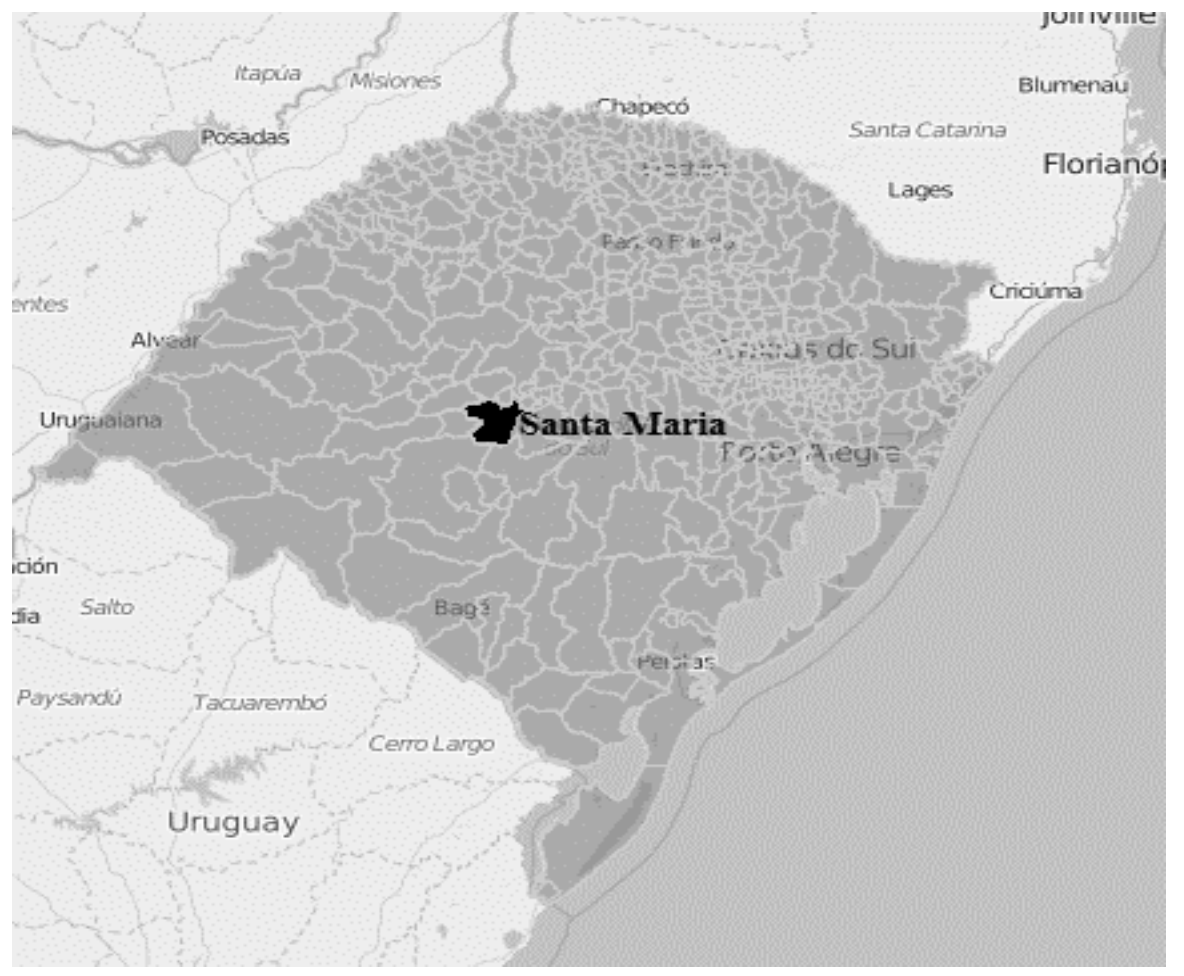

Fonte: IBGE (2010). 
Para a realização da pesquisa, confeccionou-se um instrumento com questões de ordem social e econômica adequadas às já mencionadas particularidades da metodologia fuzzy. Foram definidos sete indicadores distribuídos em duas dimensões, intituladas "Acesso a serviços de saúde e alimentação" e "Condições de habitação e acesso a serviços básicos” (Quadros 2 e 3).

Quadro 2 - Dimensão Acesso a serviços de saúde e alimentação e seus indicadores

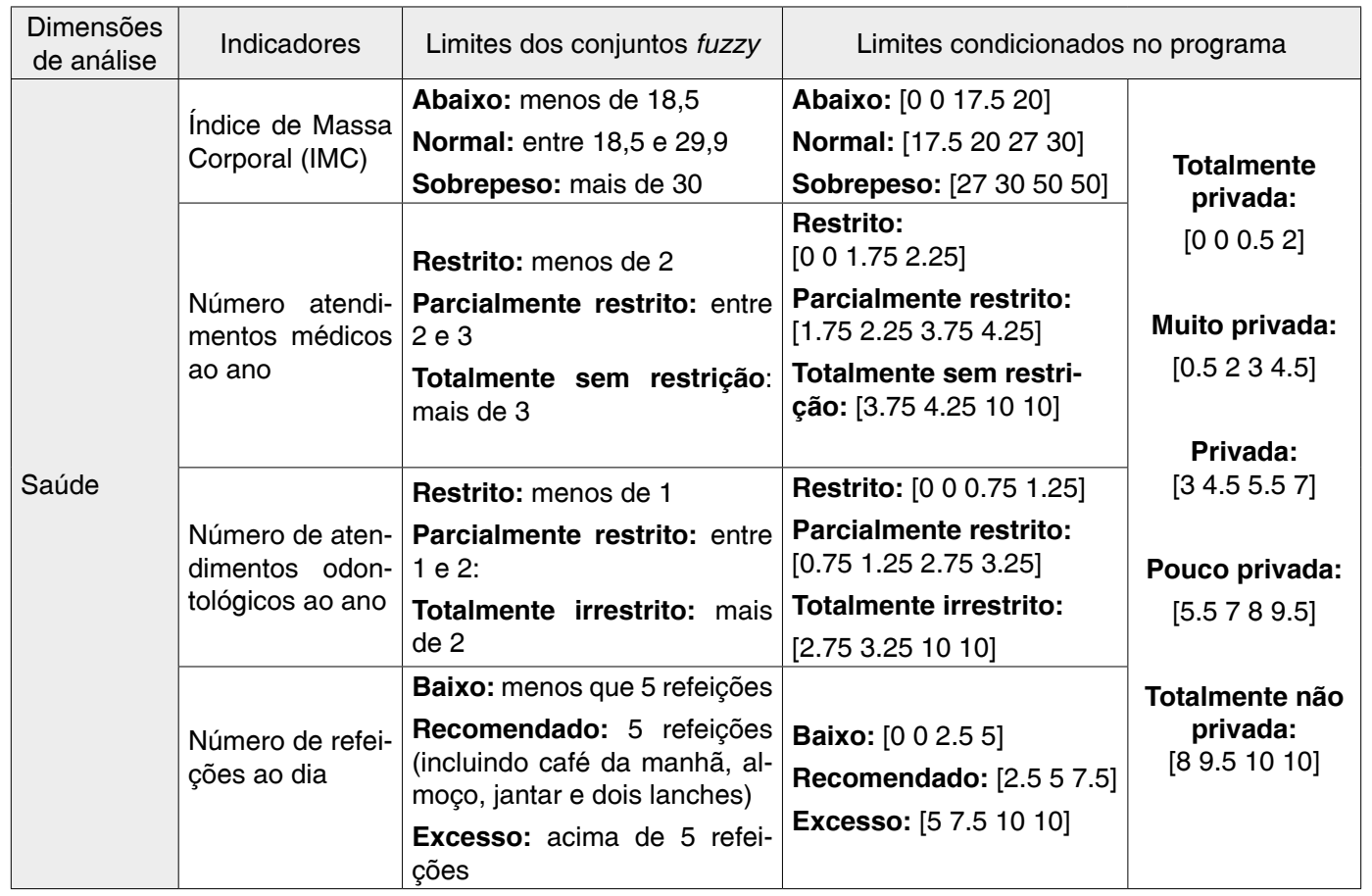

Fonte: elaboração dos autores com base na pesquisa bibliográfica sobre o tema, 2017.

A dimensão denominada "Acesso a serviços de saúde e alimentação" é composta por quatro indicadores: índice de massa corporal (IMC), número de atendimentos médicos anuais, número de atendimentos odontológicos anuais e número de refeições diárias. O primeiro indicador da dimensão saúde, o IMC, teve seus parâmetros retirados da Organização Mundial da Saúde (OMS). Portanto, considerou-se que o cidadão estará em uma situação normal de saúde quando possuir IMC entre 18,5 e 29,9; estará em estado de subnutrição quando o IMC estiver abaixo de 18,5; sobrepeso (obesidade) passa a ser considerado em situações em que o índice ultrapassa a marca dos 29,9. 
O segundo indicador da dimensão "Acesso a serviços de saúde e alimentação" é o número de consultas médicas realizadas no ano. Segundo determinação do Ministério da Saúde, na Portaria no 1.101/GM, de 12 de junho de 2002, o ideal é que os indivíduos visitem o consultório médico para realização de check-ups três vezes ao ano. Portanto, considerou-se que qualquer valor superior a esse significa inexistência de privações no âmbito do indicador. Indivíduos que fizessem duas ou três consultas anuais foram considerados parcialmente privados. E indivíduos com uma ou nenhuma consulta médica anual foram considerados em estado de privação.

O terceiro indicador da dimensão "Acesso a serviços de saúde e alimentação" é o número de atendimentos odontológicos anuais. Segundo a Academia Americana de Odontologia Pediátrica (AAPD), o esperado é que o indivíduo vá, pelo menos, duas vezes ao ano ao dentista. Portanto, considerou-se privado o indivíduo que realizou uma ou duas visitas ao dentista, e livres de privação os que compareceram três ou mais vezes no consultório odontológico.

O último indicador da dimensão "Acesso a serviços de saúde e alimentação" é o número de refeições realizadas ao dia. De acordo com o Guia alimentar para a população brasileira, desenvolvido pelo Ministério da Saúde (BRASIL, 2008), o desenvolvimento saudável do corpo se dá quando o indivíduo tem, no mínimo, cinco refeições diárias. Tendo isso em vista, considerou-se que valores abaixo do recomendado pelo Ministério da Saúde (2008) poderiam representar estados de privação. Além disso, os pesquisadores consideraram, no âmbito da pesquisa, que um número superior a cinco pudesse ser um indicativo de distúrbios alimentares ou de práticas inadequadas, de modo que também fosse considerado como indicativo de privação.

A segunda dimensão considerada neste estudo e que agrega um número considerável de aspectos da vida dos indivíduos é intitulada "Condições de habitação e acesso a serviços básicos”. Em específico, é composta por três indicadores: densidade de ocupação de dormitórios; acesso a equipamentos e eletrodomésticos; e acesso a serviços gerais. 
Quadro 3 - Dimensão Condições de habitação e acesso a serviços básicos e seus indicadores

\begin{tabular}{|c|c|c|c|c|}
\hline \multirow{2}{*}{$\begin{array}{l}\text { Dimensões de } \\
\text { análise }\end{array}$} & \multirow{2}{*}{\begin{tabular}{|l|} 
Indicadores \\
\\
Densidade por \\
dormitório
\end{tabular}} & \multirow[b]{2}{*}{$\begin{array}{l}\text { Limites dos conjuntos fuzzy } \\
\text { Baixa densidade: existir até dois } \\
\text { moradores por dormitório nos } \\
\text { domicílios. } \\
\text { Densidade ideal: existir de três a } \\
\text { quatro moradores por dormitório } \\
\text { nos domicílios. } \\
\text { Alta densidade: existir mais de } \\
\text { cinco moradores por dormitório } \\
\text { nos domicílios. }\end{array}$} & \multicolumn{2}{|c|}{ Limites condicionados no programa } \\
\hline & & & 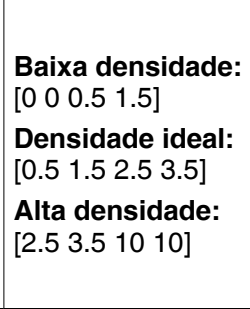 & $\begin{array}{c}\text { Totalmente } \\
\text { privada: } \\
{\left[\begin{array}{lll}0 & 0 & 0.5\end{array}\right]}\end{array}$ \\
\hline \multirow[t]{2}{*}{$\begin{array}{l}\text { Condições de } \\
\text { habitação e } \\
\text { acesso a servi- } \\
\text { ços básicos }\end{array}$} & $\begin{array}{l}\text { Número de } \\
\text { equipamentos } \\
\text { disponíveis no } \\
\text { domicílio* }\end{array}$ & $\begin{array}{l}\text { Baixo: possuir mais que } 6 \text { equi- } \\
\text { pamentos } \\
\text { Médio: possuir entre } 4 \text { e } 5 \text { equi- } \\
\text { pamentos } \\
\text { Alta: possuir } 3 \text { ou menos equipa- } \\
\text { mentos }\end{array}$ & 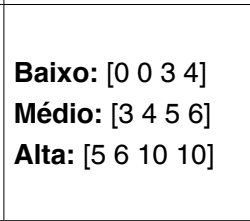 & $\begin{array}{l}\text { Privada: } \\
\text { [3 } 4.55 .57] \\
\text { Pouco privada: } \\
\text { [5.5 } 78 \text { 9.5] }\end{array}$ \\
\hline & $\begin{array}{l}\text { Serviços bási- } \\
\text { cos acessados } \\
\text { pelo indivíduo** }\end{array}$ & $\begin{array}{l}\text { Baixo: desfrutar de } 6 \text { ou mais } \\
\text { serviços básicos } \\
\text { Médio: desfrutar de } 3 \text { a } 5 \text { serviços } \\
\text { básicos } \\
\text { Alto: desfrutar de } 2 \text { ou menos } \\
\text { serviços básicos }\end{array}$ & $\begin{array}{l}\text { Baixo: }\left[\begin{array}{llll}0 & 0 & 2 & 3\end{array}\right] \\
\text { Médio: }\left[\begin{array}{llll}2 & 3 & 4 & 5\end{array}\right] \\
\text { Alta: }\left[\begin{array}{lllll}5 & 10 & 10\end{array}\right]\end{array}$ & 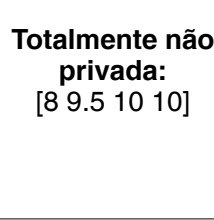 \\
\hline
\end{tabular}

Fonte: elaboração dos autores com base na pesquisa bibliográfica sobre o tema, 2017.

*Equipamentos considerados: geladeira, fogão a gás, TV e rádio, telefone celular, ventilador, ar condicionado, chuveiro elétrico, liquidificador e computador.

**Serviços básicos considerados: energia elétrica, água encanada/tratada/poço, drenagem para o esgoto/poço negro, iluminação pública, serviço de coleta de lixo, transporte público na comunidade.

O primeiro indicador desta dimensão, a densidade por dormitório, é calculado de acordo com os parâmetros definidos pelo IBGE. Consiste na divisão do número de moradores pelo número de dormitórios na residência e, para fins da presente pesquisa, é considerado ideal quando estiver entre três e quatro indivíduos.

O segundo indicador da dimensão "Condições de habitação e acesso a serviços básicos" é o número de equipamentos existentes no domicílio. Para tal propósito, foi elencada uma lista de equipamentos comumente encontrados nos domicílios de classe média brasileiros e contabilizados nos domicílios sob análise. Tais equipamentos foram: geladeira, fogão a gás, televisão/rádio, telefone celular, ventilador, ar condicionado, chuveiro elétrico, liquidificador e computador. Considerou-se que a posse é baixa (e que, portanto, o indivíduo está em estado de privação) quando o domicílio dispuser de menos de três desses equipamentos; um estado de privação parcial se daria em domicílios com quatro ou cinco; e um estado de não privação se daria em casas equipadas com seis ou mais. 
O último indicador desta dimensão, acesso aos serviços de utilidade pública, consistiu na contagem dos serviços disponíveis na residência, dentre os previamente elencados na lista dos pesquisadores. Tais serviços foram: energia elétrica, drenagem de esgoto, água encanada, iluminação pública, coleta de lixo, internet e transporte público. Considerou-se privados os domicílios que contassem com dois ou menos desses serviços; parcialmente privados os domicílios que contassem com algo entre três e cinco; e não privados os domicílios que dispusessem de mais de seis.

\section{Análise de resultados}

Os resultados parciais que demonstram as privações sofridas pelos idosos moradores dos bairros da região nordeste de Santa Maria, RS, nas dimensões acesso a serviços de saúde e alimentação e condições de habitação e acesso a serviços básicos, estão disponíveis no Quadro 4.

Quadro 4 - Resultados parciais para as dimensões pesquisadas

\begin{tabular}{|c|c|c|c|c|}
\hline \multirow{2}{*}{$\begin{array}{l}\text { Dimensão } \\
\text { analisada }\end{array}$} & \multicolumn{4}{|c|}{ Situações estimadas para os habitantes amostrados } \\
\hline & Característica da estimativa & $\begin{array}{c}\% \text { da } \\
\text { amostra }\end{array}$ & Indicador & $\%$ da amostra \\
\hline \multirow{9}{*}{$\begin{array}{l}\text { Acesso a servi- } \\
\text { ços de saúde e } \\
\text { alimentação }\end{array}$} & Totalmente desfavorável & $0,0 \%$ & \multirow[b]{2}{*}{ 1) IMC } & \multirow{2}{*}{$\begin{array}{l}\text { Abaixo: } 2,6 \% \\
\text { Normal: } 81,3 \% \\
\text { Sobrepeso: } 16,1 \%\end{array}$} \\
\hline & $\begin{array}{l}\text { Totalmente desfavorável/Muito des- } \\
\text { favorável }\end{array}$ & $3,6 \%$ & & \\
\hline & Muito desfavorável & $11,5 \%$ & \multirow{2}{*}{$\begin{array}{l}\text { 2) Número de } \\
\text { atendimentos } \\
\text { médicos }\end{array}$} & \multirow{2}{*}{$\begin{array}{l}\text { Restrito: } 19,8 \% \\
\text { Parcialmente restrito: } 40,6 \% \\
\text { Totalmente sem restrição: } 39,6 \%\end{array}$} \\
\hline & Muito desfavorável/(Des)favorável & $39,1 \%$ & & \\
\hline & (Des)favorável & $25,0 \%$ & \multirow{2}{*}{$\begin{array}{l}\text { 3) Número de } \\
\text { atendimentos } \\
\text { odontológicos }\end{array}$} & \multirow{2}{*}{$\begin{array}{l}\text { Restrito: } 45,3 \% \\
\text { Parcialmente restrito: } 37,0 \% \\
\text { Totalmente sem restrição: } 17,7 \%\end{array}$} \\
\hline & (Des)favorável/Muito favorável & $17,2 \%$ & & \\
\hline & Muito favorável & $2,6 \%$ & \multirow{3}{*}{$\begin{array}{l}\text { 4) Número de } \\
\text { refeições }\end{array}$} & \multirow{3}{*}{$\begin{array}{l}\text { Baixo: } 87,5 \% \\
\text { Recomendado: } 7,8 \% \\
\text { Excesso: } 4,7 \%\end{array}$} \\
\hline & Muito favorável/Totalmente favorável & $1,0 \%$ & & \\
\hline & Totalmente favorável & $0,0 \%$ & & \\
\hline \multirow{9}{*}{$\begin{array}{l}\text { Condições de } \\
\text { habitação e } \\
\text { acesso a servi- } \\
\text { ços básicos }\end{array}$} & Totalmente desfavorável & $0,0 \%$ & \multirow{3}{*}{$\begin{array}{l}\text { 1) Densidade } \\
\text { por dormitório }\end{array}$} & \multirow{3}{*}{$\begin{array}{l}\text { Baixo: } 48,4 \% \\
\text { Ideal: } 34,4 \% \\
\text { Alta: } 17,2 \%\end{array}$} \\
\hline & $\begin{array}{l}\text { Totalmente desfavorável/Muito des- } \\
\text { favorável }\end{array}$ & $0,0 \%$ & & \\
\hline & Muito desfavorável & $0,5 \%$ & & \\
\hline & Muito desfavorável/(Des)favorável & $0,0 \%$ & \multirow{3}{*}{$\begin{array}{l}\text { 2) Número de } \\
\text { equipamentos } \\
\text { disponíveis no } \\
\text { domicílio } \\
\end{array}$} & \multirow{3}{*}{$\begin{array}{l}\text { Baixo: } 98,4 \% \\
\text { Médio: } 1,0 \% \\
\text { Alto: } 0,5 \%\end{array}$} \\
\hline & (Des)favorável & $9,9 \%$ & & \\
\hline & (Des)favorável/Muito favorável & $0,5 \%$ & & \\
\hline & Muito favorável & $39,1 \%$ & \multirow{3}{*}{$\begin{array}{l}\text { 3) Serviços } \\
\text { básicos aces- } \\
\text { sados pelo } \\
\text { indivíduo }\end{array}$} & \multirow{3}{*}{$\begin{array}{l}\text { Baixo: } 76,6 \% \\
\text { Médio: } 22,4 \% \\
\text { Alto: } 1,0 \%\end{array}$} \\
\hline & Muito favorável/Totalmente favorável & $50,0 \%$ & & \\
\hline & Totalmente favorável & $0,0 \%$ & & \\
\hline
\end{tabular}

Fonte: elaboração dos autores, 2018. 
A primeira dimensão analisada é "Acesso a serviços de saúde e alimentação" e foi qualificada por quatro indicadores, a saber: IMC, número de atendimentos médicos e número de atendimentos odontológicos anuais e número de refeições diárias. Observa-se, no Quadro 4, que os idosos moradores da região nordeste de Santa Maria, RS, encontram-se entre os níveis ruim e intermediário de condições de saúde. Essa situação ocorre porque $39,1 \%$ dos indivíduos estudados estão entre uma situação muito desfavorável a (des)favorável, e $25 \%$ em um estado (des) favorável.

Esse resultado negativo é evidenciado, pois, dentre os indicadores que qualificam essa dimensão, o número de atendimentos odontológicos e o número de refeições diárias foram os que apresentaram os piores resultados. É demonstrado que $45,3 \%$ dos idosos investigados encontram-se em uma situação de restrição ao número de consultas odontológicas, ou seja, não realizaram, em um período de doze meses, consultas ao dentista. Como já observado, segundo a Academia Americana de Odontologia Pediátrica (AAPD), o recomendado é que os cidadãos realizem, pelo menos, duas visitas anuais ao odontólogo. Rosa et al. (2008) ressaltam a importância que a saúde bucal tem na promoção da qualidade de vida da pessoa idosa. Segundo os autores, a saúde bucal comprometida afeta tanto o nível nutricional, quanto diminui o bem-estar físico e mental do idoso, reduzindo, assim, o prazer desses agentes em ter uma vida social ativa.

Além desse indicador, outra questão que necessita cuidados é o número de refeições realizadas no dia, pois $87,5 \%$ dos idosos entrevistados estão em uma situação de baixo consumo de alimentos. Essa situação é constatada porque os idosos moradores da região nordeste de Santa Maria, RS, estão realizando de uma a quatro refeições diárias, quantidade que não é recomendada pelo Ministério da Saúde (2008), como demonstrado anteriormente. Malta, Papini e Corrente (2013), em um estudo que objetivava avaliar a qualidade da dieta da população idosa do município de Avaré, SP, também evidenciaram a inadequabilidade da alimentação dos idosos. Tais autores ressaltam a importância de os indivíduos com mais de 60 anos obterem uma alimentação rica e variada, uma vez que é um grupo etário com grande prevalência de doenças crônicas e que, devido a esse fator de risco, necessitam evitar desequilíbrios nutricionais, de modo a conseguirem obter longevidade e melhor qualidade de vida.

Porém, mesmo que sejam visíveis essas questões deficitárias no meio da saúde, vale ressaltar alguns pontos positivos encontrados pela presente pesquisa. No

Teoria e Evidência Econômica - a. 25, n. 53, p. 224-242, jul./dez. 2019 
Quadro 4, vê-se que 81,3\% da amostra possuem o IMC normal, ou seja, mesmo que o consumo de alimentos não seja adequado, os idosos procuram manter seu peso em um nível normal. Esse resultado pode ser justificado, pois grande parte dos entrevistados relatou realizar regularmente algum tipo de atividade física. Outro ponto favorável é quanto ao número de consultas médicas realizadas, 40,6\% dos entrevistados são parcialmente restritos nesse tema, enquanto que 39,6\% estão em uma situação de total não privação. Esse resultado pode ser esclarecido, pois grande parte dos indivíduos que participaram da pesquisa argumentou que, mesmo os postos de saúde não dispondo de todos os recursos necessários para realizar atendimentos de qualidade, nunca faltou assistência. Além disso, a maior parte dos participantes relatou possuir algum tipo de plano de saúde privado.

Visualizando os resultados obtidos pelo índice de saúde médio fuzzy, presente na Figura 3, observa-se que os idosos da região nordeste de Santa Maria, RS, em média, possuem um indicador de saúde no valor de 4,3940, o que evidencia precárias condições de saúde desses idosos. Esse índice demonstra que os indivíduos entrevistados estão $70 \%$ presentes em uma situação (des)favorável e 30\% em condição muito desfavorável.

Figura 3 - Índice fuzzy médio para condição de acesso a saúde e alimentação

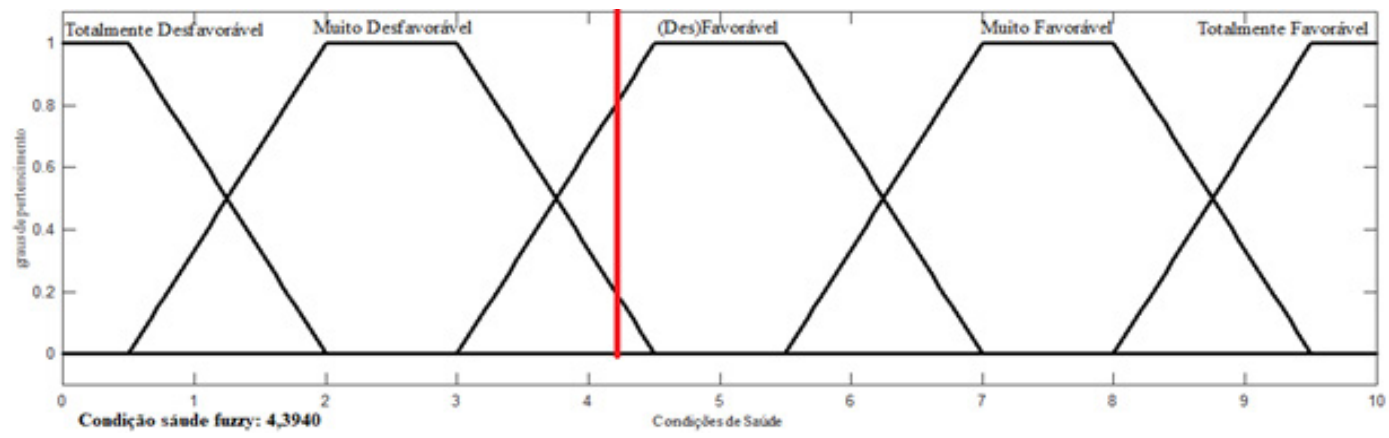

Fonte: elaboração dos autores.

A segunda dimensão é "Condições de habitação e acesso a serviços básicos" e possui três indicadores: densidade por dormitório, número de equipamentos disponíveis no domicílio e serviços básicos acessados pelo indivíduo. É constatado, pelo Quadro 4, que os idosos da região nordeste de Santa Maria, RS, encontram-se em uma situação ótima. Esse resultado é evidente porque 50\% das pessoas na terceira idade estão em uma situação de muito a totalmente favorável. 
Esse resultado positivo é constatado pois as conclusões retiradas de cada um dos indicadores, que qualificam essa dimensão, foram muito favoráveis. É visto que 48,4\% dos idosos moram em residências com baixa densidade por dormitório, ou seja, em cada uma das peças da casa, há no máximo duas pessoas residindo. Em relação ao número de equipamentos domésticos que a terceira idade dispõe em suas casas, $98,4 \%$ são não privados. Isso ocorre porque a totalidade das casas possui mais de seis equipamentos domésticos, os utensílios incluem geladeira, fogão a gás, TV e rádio, telefone celular, ventilador, ar condicionado, chuveiro elétrico, liquidificador e computador.

Também foram considerados os serviços básicos que o poder público oferece à população, constatando-se que $76,6 \%$ dos idosos não são privados. Essa situação ocorre porque os indivíduos da terceira idade são atendidos em mais de seis serviços públicos, que incluem energia elétrica, água encanada/tratada/poço, drenagem para o esgoto/poço negro, iluminação pública, serviço de coleta de lixo, transporte público na comunidade. De uma maneira geral, é evidenciado que os idosos moradores da região nordeste de Santa Maria convivem com uma boa infraestrutura, tanto de suas casas como de seus bairros.

Os resultados demonstrados no quesito condições de moradia e acesso a serviços básicos são corroborados com a análise do índice fuzzy médio, o qual dispõe de um valor de 8,16. Por esse valor é possível observar, pela Figura 4, que os idosos da região nordeste de Santa Maria pertencem $90 \%$ a uma situação muito favorável e $10 \%$ a uma condição totalmente favorável.

Figura 4 - Índice fuzzy médio para condição de acesso a habitação e serviços básicos

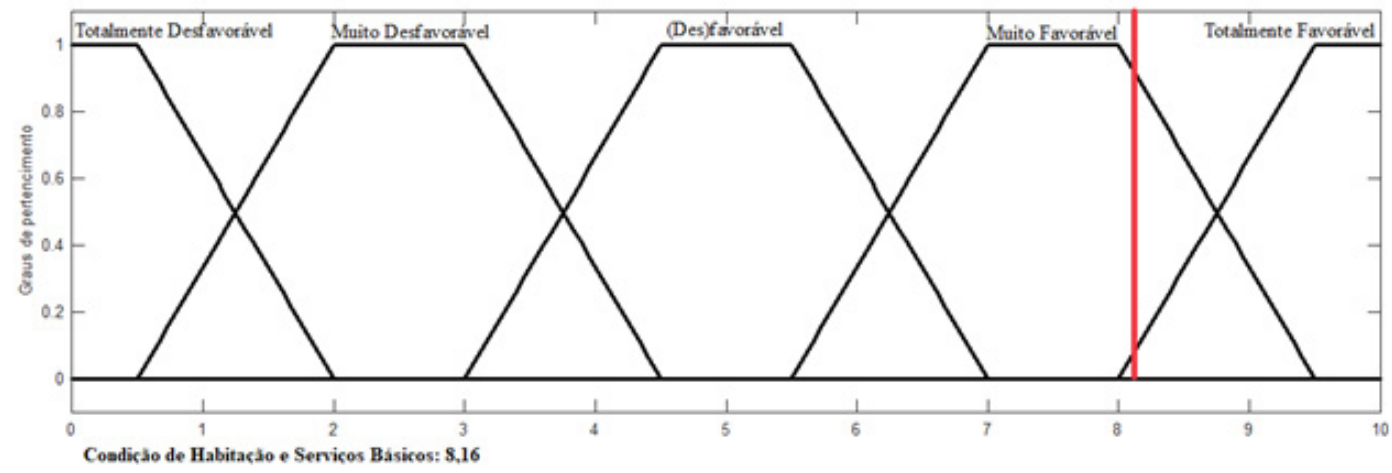

Fonte: elaboração dos autores, 2018. 
Portanto, fica evidente que os idosos, mesmo dispondo de ótima infraestrutura em suas residências e em seus bairros, ainda passam por situações precárias no acesso a serviços de saúde. Dessa maneira, destaca-se a necessidade de um esforço maior por parte da governança para promoção de políticas públicas voltadas para a melhora da qualidade de vida da população idosa. Segundo a OMS (2005), os idosos que passam pelo processo de envelhecimento com oportunidades de promoção de saúde, participação em sociedade e nível de segurança conseguem contribuir ativamente com o seu país, sua comunidade e sua família. Portanto, reitera-se que 0 desenvolvimento econômico de uma sociedade está diretamente relacionado com as ações de promoção do desenvolvimento humano. Essa relação é firmada, uma vez que, quando há incentivos para melhora da qualidade de vida e bem-estar social para população idosa, o retorno econômico para a sociedade é muito maior, pois são dados o incentivo e a oportunidade de tornarem-se cada vez mais ativos no meio em qual convivem.

\section{Conclusão}

As condições de saúde dos indivíduos são um meio de promoção tanto do desenvolvimento econômico como do desenvolvimento humano. As pessoas, quando não enfermas e com boas condições físicas, conseguem se tornar prósperas, pois a boa saúde as leva a executarem de forma eficiente seus ofícios. O desenvolvimento humano também se alimenta das condições de saúde, uma vez que pessoas mais ativas em sociedade e com maior qualidade de vida tendem a desfrutar de grandes oportunidades sociais. Além disso, é evidenciado por muitos autores que a condição de saúde é um dos fatores responsáveis pela perpetuação dos níveis de pobreza.

Dentro dessa pauta, é vigorada a discussão acerca do processo de envelhecimento saudável da população e do retorno econômico para a sociedade. Nesse debate, é demonstrado que o elevado número de idosos leva à formação de déficits nas contas públicas. Porém, essa visão nebulosa tem sido discutida por vários autores que defendem a ideia de que, ao promover o aumento da qualidade de vida da terceira idade, o retorno econômico será muito maior. Isso ocorre porque, ao se gerar políticas públicas promotoras do desenvolvimento humano e social dos idosos, esses indivíduos conseguem integrar-se no meio em que vivem, sentindo-se parte da sociedade. 
Nessa perspectiva, este trabalho objetivou analisar a situação do acesso e das condições de saúde dos idosos residentes na região nordeste de Santa Maria, RS. Foi demonstrado que a terceira idade da localidade estudada apresenta grandes déficits, principalmente nas questões de consultas odontológicas e alimentação saudável. Esses fatores são agravantes no processo de envelhecimento saudável e responsáveis pela vida não ativa dos idosos da região em estudo. Dessa maneira, destaca-se a necessidade do fomento, por parte do poder público, de políticas voltadas para a inclusão do idoso no meio em que vive. Sendo essas ações de extrema importância para o desenvolvimento humano e social da terceira idade.

\title{
Human development under the perspective of living more and better: analysis of access and health conditions in the elderly population of Santa Maria (RS)
}

\begin{abstract}
The process of aging of the Brazilian population has challenged the Brazilian State as to its ability to meet the demands of the elderly. In fact, the expansion of the elderly population in the country motivates reflections on the instruments developed in favor of social security. In view of this context, the present study aims to analyze the access and health conditions of elderly residents in the northeast region of Santa Maria, RS. For this purpose, bibliographical and documentary research on the subject was carried out, as well as field research. The primary data collected during the intersection of 2015 and 2016 were manipulated through the fuzzy method, which allowed to analyze the existence of deprivations in health, the indicators in which they are focused and the degree of recurrence that are perceived by the elderly population of said municipality. The results indicate high deprivation in access to health and food services, specifically in dental consultations and daily meals.
\end{abstract}

Keywords: Health economics. Fuzzy set theory. Human development. 


\title{
El desarrollo humano bajo la perspectiva de vivir más y mejor: análisis del acceso y las condiciones de salud en la población mayor de Santa María (RS)
}

\author{
Resumen
}

\begin{abstract}
El proceso de envejecimiento de la población brasileña ha desafiado al Estado brasileño en términos de su capacidad para satisfacer las demandas de los estratos sociales compuestos por ancianos. De hecho, la expansión de la población anciana en el país motiva reflexiones sobre los instrumentos desarrollados a favor de la seguridad social. En este contexto, el presente estudio tiene como objetivo analizar el acceso y las condiciones de salud de los ancianos residentes en la región noreste de Santa María (RS). Para ello se realizó una investigación bibliográfica y documental, así como una investigación de campo. Los datos primarios recolectados durante los intersticios de 2015 y 2016 fueron manipulados mediante el método difuso, que permitió analizar la existencia de privaciones en salud, los indicadores en los que se enfocan y el grado de recurrencia que son percibidos por la población anciana de ese municipio. Los resultados indican una alta privación en el acceso a los servicios de salud y alimentación, específicamente en las consultas dentales y las comidas diarias.
\end{abstract}

Palabras clave: Economía de la salud. Teoría de conjuntos difusos. Desarrollo humano.

\section{Referências}

ACADEMIA AMERICANA DE ODONTOLOGIA PEDIÁTRICA. Frequently Asked Questions. Disponível em: http://www.aapd.org/resources/frequently_asked_questions/\#43. Acesso em: 15 dez. 2017.

ANTUNES, J. Lógica nebulosa para avaliar riscos na auditoria. Revista Contabilidade \& Finanças, São Paulo, v. 17, p. 80-91, 2006.

BARATA, R. B. Como e por que as desigualdades sociais fazem mal à saúde. Rio de Janeiro: Editora Fiocruz, 2009.

CAMACHO, A. C. L. F.; COELHO, M. J. Políticas públicas para a saúde do idoso: revisão sistemática. Revista Brasileira de Enfermagem, Brasília, v. 63, n. 2, p. 279-284, 2010.

CASSOL, A.; NIEDERLE, P. A. Celso Furtado e a econômica política do desenvolvimento latino-americano. In: NIEDERLE, P. A.; RADOMSKY, G. F. W. (org.). Introdução às teorias do desenvolvimento. Porto Alegre: Editora da UFRGS, 2016. p. 29-38.

COSTA, C. K. F. et al. Envelhecimento populacional e a necessidade de reforma da saúde pública e da previdência social brasileiras. A Economia em Revista, Maringá, v. 19, n. 2, p. 121-131, 2012.

DEATON, A. Health, inequality, and economic development. Journal of Economic Literature, v. 41, n. 1, p. 113-158, 2003. 
GIACOMELLI, G. S.; MARIN, S. R.; FEISTEL, P. R. Da economia tradicional do bem-estar à Abordagem das Capacitações e a importância da equidade em saúde para o desenvolvimento humano. Nova Economia, Belo Horizonte, v. 27, n. 1, p. 89-115, 2017.

HELLER, L. Relação entre saúde e saneamento na perspectiva do desenvolvimento. Ciência \& Saúde Coletiva, Rio de Janeiro, v. 3, p. 73-84, 1998.

INSTITUTO BRASILEIRO DE GEOGRAFIA E ESTATÍSTICA (IBGE). Cidades. Disponível em: https://cidades.ibge.gov.br/brasil/rs/santa-maria. Acesso em: 19 jun. 2018.

INSTITUTO BRASILEIRO DE GEOGRAFIA E ESTATÍSTICA (IBGE). Censo Demográfico. 2010. Disponível em: https://censo2010.ibge.gov.br/. Acesso em: 15 jul. 2018.

JANÉ, D. A. Uma introdução ao estudo da lógica fuzzy. Hórus - Revista de Humanidades e Ciências Sociais Aplicadas, Ourinhos, n. 2, p. 1-16, 2004.

MALTA, M. B.; PAPINI, S. J.; CORRENTE, J. E. Avaliação da alimentação de idosos de município paulista: aplicação do Índice de Alimentação Saudável. Ciência e Saúde Coletiva, Rio de Janeiro, v. 18, n. 2, 2013.

MARRO, A. A. et al. Lógica fuzzy: conceitos e aplicações. Universidade Federal do Rio Grande do Norte, 2010.

BRASIL. Ministério da Saúde. Guia alimentar para a população brasileira: promovendo a alimentação saudável. 2008. Disponível em: http://bvsms.saude.gov.br/bvs/publicacoes/guia_alimentar_populacao_brasileira_2008.pdf. Acesso em: 15 dez. 2017.

NOVIGNON, J. et al. Health and vulnerability to poverty in Ghana: evidence from the Ghana Living Standards Survey Round 5. Health Economics Review, v. 2, n. 1, p. 11, 2012.

ORGANIZAÇÃO MUNDIAL DA SAÚDE (OMS). Envelhecimento ativo: uma política de saúde. Organização Pan-Americana da Saúde, 2005.

PEREIRA, R. J. et al. Influência de fatores sociossanitários na qualidade de vida dos idosos de um município do Sudeste do Brasil. Ciência \& Saúde Coletiva, Rio de Janeiro, v. 16, p. 29072917, 2011.

ROSA, L. et al. Odontogeriatria - a saúde bucal na terceira idade. Revista da Faculdade de Odontologia da UPF, Passo Fundo, v. 13, n. 2, 2008.

SEN, A. Health in development. Bulletin of the World Health Organization, v. 77, n. 8, p. 619, 1999. SEN, A. Desenvolvimento como liberdade. São Paulo: Schwarcz S.A., 2010.

SOUSA, L.; GALANTE, H.; FIGUEIREDO, D. Qualidade de vida e bem-estar dos idosos: um estudo exploratório na população portuguesa. Revista de Saúde Pública, São Paulo, v. 37, p. 364-371, 2003.

WAGSTAFF, A. et al. Child health: reaching the poor. American Journal of Public Health, v. 94, n. 5, p. 726-736, 2004. 